\title{
Refractory Bladder Carcinoma
}

National Cancer Institute

\section{Source}

National Cancer Institute. Refractory Bladder Carcinoma. NCI Thesaurus. Code C150316.

Bladder carcinoma that does not respond to treatment. 